\title{
A novel method for optical subcarrier label generation
}

\section{Zhang, Jianfeng; Chi, Nan; Holm-Nielsen, Pablo Villanueva; Peucheret, Christophe; Jeppesen, Palle}

\section{Published in:}

Optical Fiber Communication Conference 2003

Link to article, DOI:

10.1109/OFC.2003.1248474

Publication date:

2003

Document Version

Publisher's PDF, also known as Version of record

Link back to DTU Orbit

Citation $(A P A)$ :

Zhang, J., Chi, N., Holm-Nielsen, P. V., Peucheret, C., \& Jeppesen, P. (2003). A novel method for optical subcarrier label generation. In Optical Fiber Communication Conference 2003 (Vol. 2, pp. TuQ5). IEEE. https://doi.org/10.1109/OFC.2003.1248474

\section{General rights}

Copyright and moral rights for the publications made accessible in the public portal are retained by the authors and/or other copyright owners and it is a condition of accessing publications that users recognise and abide by the legal requirements associated with these rights.

- Users may download and print one copy of any publication from the public portal for the purpose of private study or research.

- You may not further distribute the material or use it for any profit-making activity or commercial gain

- You may freely distribute the URL identifying the publication in the public portal 
Hatakeyama, H.; Tamanuki, T.; Sasaki, T, "Hybrid integrated symmetric Mach-Zehnder alloptical switch with ultrafast, high extinction switching," Electron. Lett., 35, 23, p. 2030, 1999. [3] Uchiyama $\mathrm{K}$. and Morioka T., "All-optical signal processing for $160 \mathrm{Gbit} / \mathrm{s} / \mathrm{channel}$ OTDM/ $4,2001$.

[4] Akiyama, T.; Wada, O., "Beat-detect OTDM demultiplexer," Lightwave Technology, 19, 9, p. $1326,2001$.

[5] Lee, J.H.; Teh, P.C.; Petropoulos, P.; Ibsen, M.; Richardson, D.J., "Timing jitter tolerant alloptical modulator and demultiplexing system incorporating pulse-shaping fiber Bragg gratings," OFC 2001, 4, PD30 -P1-3, vol. 4, 2001.

[6] Nonoka K., Uchiyama $\mathrm{K}$, and Takara $\mathrm{H}$. "Picosecond optical pulse timing control using double pulses," ECOC 1999, 2, p. 40, 1999. [7] Kato M., Fujiura K., and Kurihara T., "Singlechannel $800 \mathrm{Gbit/s}$ asynchronous all-optical amplitude-division demultiplexing based on polarization-independent $\mathrm{GHz}$ Raman soliton in fiber," CLEO'2002, Postdeadline paper, CPDB4, 2002. [8] Kato M., Kurokawa K., Fujiura K., Kurihara T., and K. Okamoto, "High bit rate and programmable multiwavelength generator based on Raman soliton effect in DSF," Electron. Lett., 38, p. 164,2002 .

[9] Mitschke F. M. and Mollenauer L. F., "Discovery of the soliton self-frequency shift," Opt. Lett., 11, p. 659, 1986

[10] Gordon J. P., "Theory of the soliton self-frequency shift," Opt. Lett., 11, p. 662, 1986.

[11] Kurokawa K., Kubota H., and Nakazawa M., "Soliton self-frequency shift accelerated by femtosecond soliton interaction," Electron. Lett., 28 , p. 2056, 1992.

A Novel Method For Optical Subcarrier Label Generation

J. Zhang, N. Chi, P. Holm-Nielsen, C. Peucheret, P. Jeppesen, Technical University of Denmark, Kgs.Lyngby,Denmark,Email: jz@com.diu.dk.

We propose a novel architecture for an optical subcarrier label transmitter. An optical signal consisting of a $10 \mathrm{~Gb} / \mathrm{s}$ payload and a $156 \mathrm{Mb} / \mathrm{s}$ label was generated, and its performance was evaluated in a transmission link

\section{Introduction}

All optical label switching implements the packet routing and forwarding functions of multiprotocol label switching (MPLS) directly in the optical layer, which is a promising technology for the next generation wavelength division multiplexing (WDM) networks. Several optical labeling methods have been proposed [1]-[4], and the optical subcarrier label has been demonstrated as an efficient solution.

Regarding to the different generation schemes of the optical subcarrier label, the optical packet can be labeled electro-optically in a differential MachZehnder modulator [1] [3], or optically in an optical multiplexer [1]. The former one is simple to implement, but it introduces interference between the packet and label through intermodulation distortion. The latter overcomes some of the disadvantages, however, it requires narrow-bandwidth filtering using birefringent devices, thus increasing the complexity of the transmitter. Both schemes also require the analogue $R F$ mixers to perform the subcarrier multiplexing, which increase the system cost and complexity.

In this paper, we propose and experimentally demonstrate a novel method to optically label the optical baseband packet by using the carrier suppression technique. Unlike the previous designs, it permits an arbitrary label to payload power ratio, and doesn't introduce any penalty to both label and payload in principle. The generated signal consists of $\mathrm{a} 10 \mathrm{~Gb} / \mathrm{s}$ payload and a $156 \mathrm{Mb} / \mathrm{s}$ label, and its performance was evaluated in a

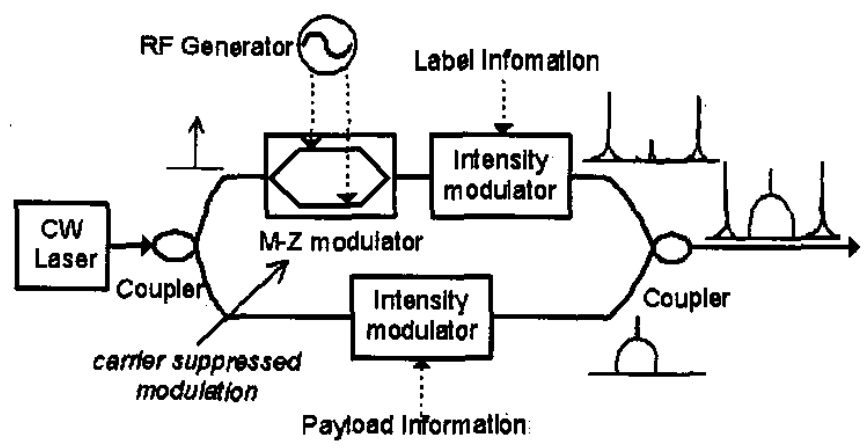

Fig. 1. The proposed architecture of the optical label transmitter (HC: hybrid coupler EDFA: erbiumdoped fiber amplifier ATT: attenuator SMF: single mode fiber DCF: dispersion compensating fiber OADM: optical add/drop multiplexer)

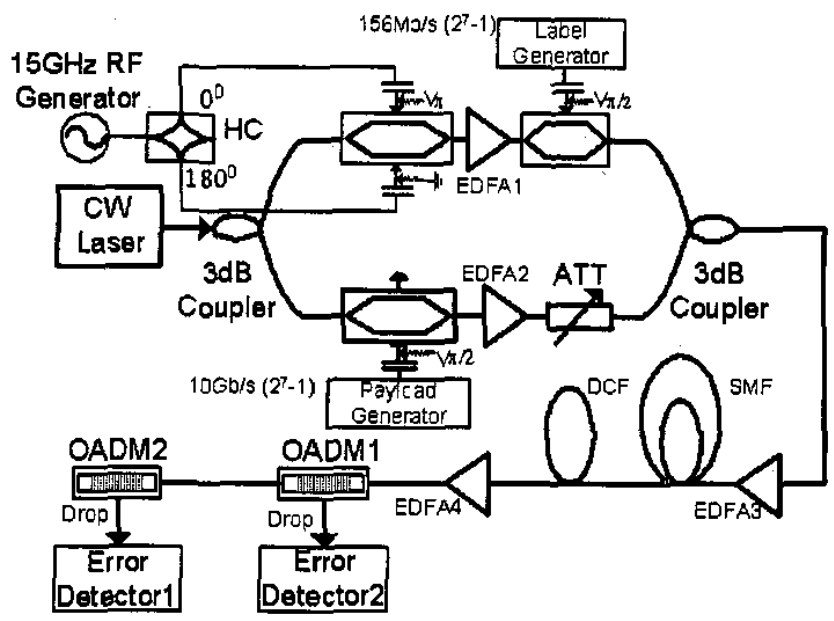

Fig. 2. The experimental setup for labeled signal transmission over 50km SMF

$50 \mathrm{~km}$ standard single-mode-fiber (SMF) transmission link.

\section{Operation Principle}

A schematic diagram of the proposed optical label transmitter is shown in Fig. 1. In this transmitter, the output of a continuous-wave laser is split through an optical coupler. The payload information is directly impressed upon one of them using an external intensity modulator. For the other arm, the light is first modulated by a differential Mach-Zehnder modulator driven by a radio-frequency (RF) clock generator. This modulator was specially configured to perform carrier suppression modulation [5], whose output mainly consists of two sidebands. Then, the label information is impressed upon the two sidebands using a conventional intensity modulator. As the generated label doesn't have the optical carrier component in its spectrum, it can be directly multiplexed with the optical payload through a coupler

The main advantage of the transmitter is that the label and payload can be controlled independently, and there is no intermodulation distortion between them. Another advantage is that it doesn't require the use of RF mixers or optical notch filters, which reduces the system complexity.

\section{Experimental Setup and Results}

Our experimental setup is shown in Fig. 2. A dual arm $\mathrm{LiNbO} 3 \mathrm{MZ}$ modulator, which has a $3 \mathrm{~dB}$ modulation bandwidth of $15 \mathrm{GHz}$ and $3.5 \mathrm{~dB}$ insertion loss, was configured to perform the carrier-suppressed modulation in the transmitter. The DC bias difference for two arms is exactly equal to the swing voltage $\mathrm{V}_{\mathrm{T}} . \mathrm{ARF}$ clock at $15 \mathrm{GHz}$ was applied to hybrid coupler whose two outputs have $\pi$ phase shif with respect to each other. These two outputs then drove this modulator to perform the modulation. The other two MZ modulators functioned as intensity modulators to impress the $10 \mathrm{~Gb} / \mathrm{s}$ payload and
$156 \mathrm{Mb} / \mathrm{s}$ label information separately. An optical attenuator was inserted in the payload arm to adjust the relative power ratio. The generated signal at $1550 \mathrm{~nm}$ was then transmitted over $50 \mathrm{~km} \mathrm{SMF}$ and a matching length of dispersion compensating fiber (DCF). To optimize both the payload and label receivers' performance, the input power to the fiber was set to $10 \mathrm{dBm}$. At the end of transmission link, two fiber-Bragg-grating(FBG) based Optical-add/ drop-multiplexers (OADM) were used for the extraction of the payload and label from the transmitted signals. The edge of the first OADM transfer function was selected to be located between the wavelength of one sideband and the carrier. In such a way, this sideband with label information was dropped and input to the optical receiver for bit error ratio testing, the other sideband and the carrier was transferred to the second OADM, whose transfer function edge was located between them. In this way, the carrier with the payload information was dropped by the second OADM and then input to another error detector for performance evaluation. As shown in Fig. 3 (a), the carrier component in the optical label spectrum is greatly suppressed. The power ratio of carrier to sideband is measured to be below $-32 \mathrm{~dB}$, which ensured that no modulation distortion was added to the payload. In the transmitter, the label (one-sideband) to payload power ratio could be adjusted by the attenuator, and was set as $5 \mathrm{~dB}$ for the transmission system optimization, as shown in Fig. 3(b). At the receiver node one sideband label was extracted by an OADM filter, the payload is extracted with some residual label due to the not-so-steep edge of the second filter, as shown in Fig. 3 (c) (d).

The comparison of the eye-diagrams of the label and payload before multiplexing and after transmission and extraction are given in Fig. 4. The BER curves in Fig. 5 show that the penalties 


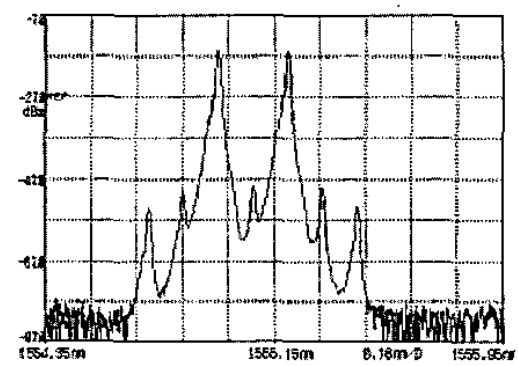

Fig. 3. Spectra of (a) the generated label with the suppressed carrier

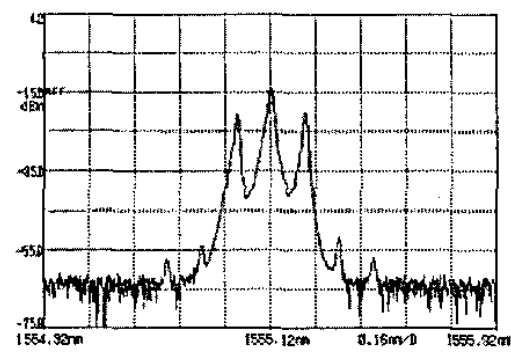

Fig. 3. (b) the generated signal consisting of payload and label

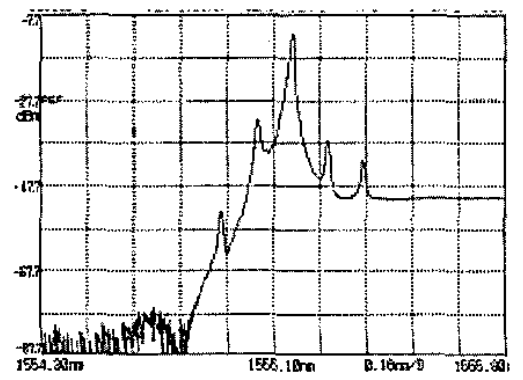

Fig. 3. (c) the extracted label after first OADM

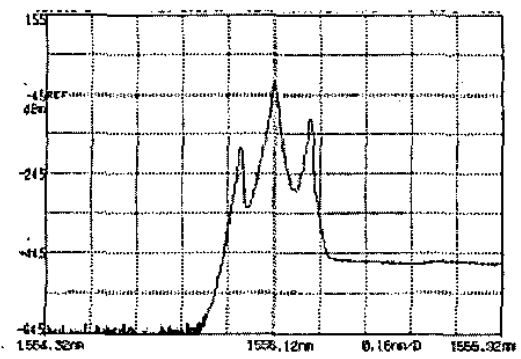

Fig. 3. (d) the payload with the residual label after second OADM.

induced by the labeling and transmission are about $0.3 \mathrm{~dB}$ for both the label and payload.

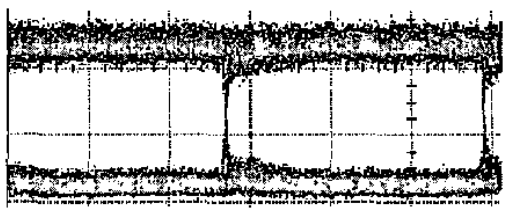

(a) 2 ns/div

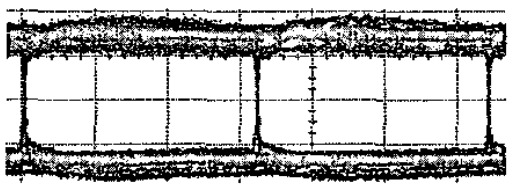

(b) 2ns/div

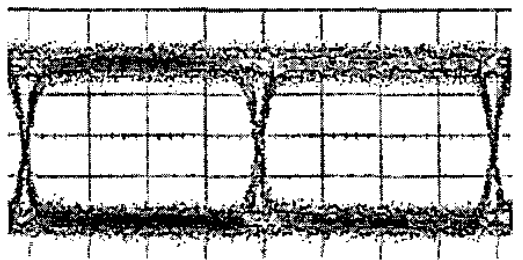

(c) $25 \mathrm{ps} / \mathrm{div}$

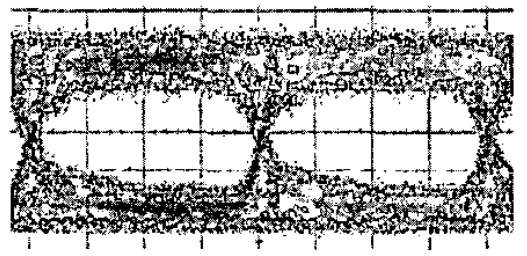

(d) $25 \mathrm{ps} / \mathrm{div}$

Fig. 4. Eye-diagrams of (a) original label before multiplexing (b) extracted label (c) original payload before multiplexing (d) extracted payload.

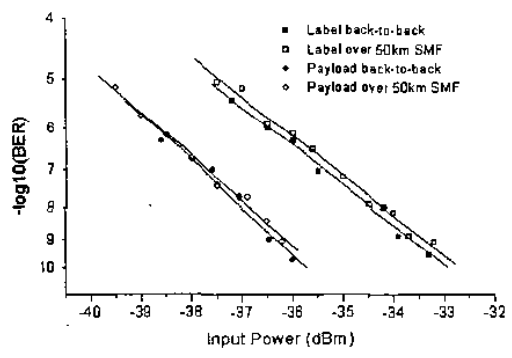

Fig. 5. Measured BER curves

\section{Conclusions}

We have proposed and demonstrated a novel method to generate an optically labeled signal by using the carrier suppression technique. The generated signal consists of a $10 \mathrm{~Gb} / \mathrm{s}$ payload and a $156 \mathrm{Mb} / \mathrm{s}$ label, and shows good performance in a $50 \mathrm{~km}$ transmission link.

\section{References}

1. D.J. Blumenthal et al, "All-optical label swapping networks and technologies" J. Lightwave Technol., v. 18, 2058-2075 (2000)

2. B. Meagher et al, "Design and implementation of ultra-Low latency optical label switching for packet-switched WDM networks," Journal Lightwave Technol., v. 18, 1978-1987 (2000) 3. Y.M. Lin et al, "A novel optical label swapping technique using erasable optical single-sideband subcarrier label," Photon. Techno. Lett., v. 12, 1088-1090 (2000)

4. T. Koonen et al, "Optical packet routing in IPover-WDM networks deploying two-level optical labelling," THL2.1, ECOC'01 (2001).

5. R. Montgomery et al, "A novel technique for double sideband suppressed carrier modulation of optical fields," IEEE Photon. Technol. Lett., v. 7, 434-436 (1995).
FD6

9:30 AM

All-Optical Wavelength and Time 2-D Code Converter for Dynamically-Reconfigurable $\mathrm{O}$ CDMA Networks Using a PPLN Waveguide

D. Gurkan, S. Kumar, A. Sahin, A. Willner, University of Southern California, Los Angeles, $C A ; \mathrm{K}$. Parameswaran, M. Fejer, Stanford University, Palo Alto, CA; D. Starodubov, Sabeus Photonics, Chatsworth, CA; J. Bannister, P. Kamath, J. Touch, University of Southern California, Marina del Rey, CA, Email. denizgurkan@ieee.org.

We demonstrate all-optical wavelength and time code conversion for O-CDMA networks at $2.5-\mathrm{Gbit} / \mathrm{s}$ with $10-\mathrm{Gchip} / \mathrm{s}$. Difference-frequency generation provides wavelength-shifting and fiberBragg gratings introduce cyclic time-shifts to the incoming code, generating a new time/wavelength code with less than $0.7-\mathrm{dB}$ power penalty.

1. 2-D OCDMA networks utilizing code-converters

There has recently been much renewed interest in optical code-division-multiple-access (O-CDMA) due to its potential for enhanced data security and spectral efficiency, especially when considering the fine granularity of traffic in local-area-networks (LANs) [i,ii]. However, a key drawback for O-CDMA has been the necessity of generating propagating, and detecting extremely short chip times (i.e the time- domain subdivisions of a bit) such that there are sufficient orthogonal codes [iii]. One approach for alleviating the small chip time has been the introduction of a two-dimensional oCDMA architecture, in which each bit is subdivided into a combination of chip times and a discrete set of wavelengths [iv, v]. Even with a time/ wavelength approach, a reasonable number of wavelengths and chip times cannot accommodate many simultaneous users. Therefore, it may be of great value for an O-CDMA network to re-use a finite set of 2-D codes across different parts of the network. Moreover, such code re-use, which is analogous to wavelength re-use in a WDM network, should be reconfigurable in order to account for changing traffic pattems and to alleviate congestion.

In general, a 2-D code converter would need to redistribute the optical energy in both dimensions, namely, the chip times and the wavelengths. $A$ brute-force electronic approach for code conversion would be to decode the O-CDMA signal using autocorrelation and threshold detection, change the code in the electronic domain, and then re-encode the data on an optical signal [vi]. A potentially more rapid, efficient and transparent approach for high-data-rate signals is to perform the code conversion in the optical domain.

Although there were generic demonstrations of all-optical wavelength conversion for wavelength routing in WDM networks and separate demonstrations of all-optical time shifting for time slot routing in TDM networks [vii], there has been no reported demonstration of an all-optical $\mathrm{O}$ CDMA 2-D code converter.

We demonstrate all-optical, wavelength and time, code conversion for OCDMA networks a a user data rate of $2.5 \mathrm{Gbit} / \mathrm{s}$ with $4 \mathrm{chips} / \mathrm{bit}$ and 2 wavelengths/code. Difference frequency generation (DFG) in a periodically-poled lithiumniobate (PPLN) waveguide enables wavelength conversion [viii] and fiber Bragg gratings (FBGs) are used to provide cyclic time shifts [vii] to the incoming code to generate a new time/wavelength code. We also demonstrate switching of input frames to code-converted frames to resolve code contention between 2 LANs sharing the same particular code. Our technique for code conversion introduces less than $0.7 \mathrm{~dB}$ power penalty.

2. Time/wavelength O-CDMA structure and code conversion

Figure 1 explains the method of our time/wavelength 2-D O-CDMA code conversion. Interconnectivity between multiple O-CDMA LANs can be made efficient by incorporating code re-use. To provide this functionality, a code converter acts as 